УДК 81`42:81`33

ББК 81.1

DOI: https://doi.org/10.17308/lic.2021.4/3807

\title{
АСПЕКТЫ РАЗГРАНИЧЕНИЯ УСТНЫХ И ПИСЫМЕННЫХ ТЕКСТОВ НА ПРИМЕРЕ ИНТЕРНЕТ-ЧАТОВ
}

\author{
Ю. И. Бутенко, Е. А. Шершнева \\ Московский государственный технический университет имени Н. Э. Баумана
}

\section{THE PROBLEM OF DISTINCTION BETWEEN ORAL AND WRITTEN TEXTS ON INTERNET CHATS MATERIAL}

\author{
Yu. I. Butenko, E. A. Shershneva \\ Bauman Moscow State Technical University
}

\begin{abstract}
Аннотация: в статье анализируется проблема различия устных и письменных текстов на основе содержания сообщений в новой коммуникаџионной среде, являющейся на данный момент неотъемлемой частью современного общества, - интернет-чатах. Актуальность работы обусловлена тем, что она способствует накоплению данных о характеристиках нового вида общения, о специфике интернет-чатов как устно-письменной формы коммуникации. Целью исследования является описание и анализ содержания чатов в сочиальных сетях и мессенджерах и новых средств общения, использующихся в них, обусловленных техническими возможностями интернет-среды, для доказательства принадлежности сообщений чатов к разному типу коммуникаций в зависимости от ряда причин. В ходе исследования применялись методь лингвистического наблюдения и описания, статистики и семантико-стилистического анализа. Результаты работы расширяют представление об особенностях интернет-чатов, связанных со спецификой их функционирования (дистантное и опосредованное общение, характерное для письменной речи) и способностью наполнения текста различными средствами коммуникации, к примеру, пиктограммами (смайль, эмодзи), являющимися некими аналогами экстралингвистических средств устного общения. Показано, что разрешение проблемы разграничения устных и письменных текстов, установление вида коммуникации у интернет-чатов не представляется возможным без анализа содержимого каждой переписки, так как некоторые интернет-чаты своей тематической направленностью, своими участниками-коммуникантами обусловливают тяготение своих сообщений больще к письменному или устному типу речи.

Ключевые слова: устные тексты, письменные тексты, виды общения, устная речь, письменная речь, интернет-чаты.
\end{abstract}

\begin{abstract}
: the article analyzes the problem of the difference between oral and written texts based on the content of messages in the new communication environment, which is currently an integral part of modern society Internet chats. The relevance of the work is due to the fact that it contributes to the accumulation of data on the characteristics of a new type of communication, on the specifics of Internet chats as an oral and written form of communication. The aim of the study is to describe and analyze the content of chat rooms in social networks and messengers and the new means of communication used in them, due to the technical capabilities of the Internet environment, to prove that chat room messages belong to a different type of communication, depending on a number of reasons. The methods of linguistic observation and description, statistics and semantic and stylistic analysis were used during the research. The results expand the idea of the peculiarities of Internet chats connected with the specifics of their functioning (distant and mediated communication, typical for written speech) and the ability to fill a text with different means of communication, for example, pictograms (smileys, emoji), which are some analogues of extralinguistic means of oral communication. It is shown that solving the problem of distinguishing between oral and written texts, the establishment of the type of communication in Internet chats is not possible without analyzing the content of each correspondence, as some Inter-
\end{abstract}

(С Бутенко Ю. И., Шершнева Е. А., 2021

Контент доступен под лицензией Creative Commons Attribution 4.0 License. The content is available under Creative Commons Attribution 4.0 License. 
net chats by their thematic focus, their participants, communicants cause the gravitation of their messages more to the written or oral type of speech.

Key words: oral texts, written texts, types of communication, oral communication, written communication, internet chats.

\section{Введение}

Литературный язык имеет две формы: устную и письменную, характеризующиеся особенностями как с лексической стороны, так и грамматической формой, поскольку они предназначены для разных типов восприятия - слухового и зрительного. Письменный литературный язык отличается от устного более сложным синтаксисом и наличием множества абстрактной лексики, а также использованием терминологической и интернациональной лексики.Текст устный или письменный обладает своими особенностями. Устное общение обычно связано с признаками контактности и спонтанности, а письменное общение - с признаками дистантности и опосредованности [1-2].

С первого взгляда решить вопрос о разграничении устных и письменных текстов несложно. Если отталкиваться от материальной формы знака, то устную речь всегда легко отличить от письменной: устная речь создается в виде звуковой материи и воспринимается акустически, а письменная речь создается в виде графической материи и оценивается визуально. Но, как утверждает Д. Бертольд, «не все, что мы слышим, можно рассматривать как устную речь (чтение резолюции), не все, что мы читаем, можно рассматривать как письменную речь» [3].

В специализированной литературе ученые вновь и вновь возвращаются к проблеме о различиях устной и письменной форм речи, выделяя тем временем естественную природу устной речи и вторичную, искусственную натуру письменной речи. Один из аргументов в пользу признания абсолютного отличия между этими речевыми формами - невозможность полного перекодирования текста из одной структуры в другую и наоборот [4].

Особенностями устной коммуникации являются сиюминутность, эфемерность сказанного, особая роль просодии, мимики и жестикуляции, а также важность ситуативного контекста для восприятия высказывания. Напротив, письменный текст сохраняется гораздо дольше, чем устный, графические средства и маркировка текста принимают на себя функцию просодии; письменный текст содержит больше языковой информации, поскольку роль экстралингвистического контекста в этом случае сводится к минимуму.

Кроме того, устная форма речи выделяется множеством грамматических ошибок, обрывами и повторными высказываниями, запинками, паузами на размышление и т. п. Наконец, в устной и письменной речи применяется различная лексика, длина предложений в письменной речи превышает длину в устной, довольно часто предложения на письме строятся по нормам, неприемлемым в устной речи. При таком противостоянии, как правило, подразумевается, что устная речь - спонтанная речь в прямом общении, а письменная речь соответствует формально выверенной книжной речи [5].

Занятный эксперимент в отношении специфики письменных текстов был проведен Е. Р. Ватсон. Она решила сравнить авторское и неавторское исполнение художественных произведений. Были сопоставлены записи отрывков, исполненных чтецами с высшим лингвистическим образованием. В то же время авторское прочтение рассматривалось как образец наиболее полного раскрытия произведения [6].

По итогу всестороннего аудиторского анализа материала определилось, что в процессе устного воспроизведения письменного литературного текста на его интонационную интерпретацию влияли три главных параметра: содержательный компонент (реализация ключевых фраз и фразовые информационные центры), форма (наличие или отсутствие многоголосия) и динамика развития текста (темп, ритм). Кроме того, каждый из этих факторов по-разному отражался в интонационной реализации текста. Выяснилось, что классические художественные тексты наиболее восприимчивы к правильной интонационной реконструкции.

С момента появления научной теории текста разные ученые пытались найти критерий, который, по мнению К. Гаузенбласа, «точно отображал бы наиболее важные отличия в структуре речевых произведений с учетом современных потребностей практики коммуникации, в том числе отличия на всех уровнях структуры речевого произведения, от самых маргинальных (звуковых и графических) до центральных уровней, связанных со структурой содержания». Поиск такого критерия был значительно осложнен тем фактом, что лингвистика текста, пытаясь охватить самые разные области исследования текста, в свое время стала превращаться в аморфную, расплывчатую и неопределенную науку и, таким образом, создала условия для размывания контуров лингвистики в целом. На этом фоне бесспорным является вывод К. Гаузенбласа о том, что «при общем анализе наиболее важные различия между устными и письменными проявлениями речевой деятельности неоспоримы» [7]. 
При изучении текстов, процессов их генерации и восприятия всегда необходимо понимать, какие речевые произведения являются объектом анализа: устные тексты, т. е. речевые произведения, записанные сначала на магнитную ленту, а затем измененные в графическую запись, или письменные тексты, т. е. речевые произведения, которые были задуманы изначально и производились в виде письменных текстов. Эти выводы подтверждаются мнением лингвистов, которые убеждены, что устные и письменные формы общения имеют глубокие структурные и существенные различия, которые позволяют говорить об их автономии. Широко известно, к примеру, категоричное утверждение И. Р. Гальперина о том, что «все особенности устной речи противоположны особенностям текста», и полагая, что «текст является своего рода образованием, которое возникло, существует и развивается в письменной версии литературного языка» [8].

Целью статьи является исследование разграничения устных и письменных текстов на материале интернет-чатов как современного средства коммуникации.

\section{Результаты и обсуждение}

Интернет-среда - это относительно новая сфера общения, которая, возникнув сравнительно недавно, привлекла внимание исследователей, представляющих различные отрасли знания, - филологов, психологов, психолингвистов, социологов и др. Изучению различных лингвистических аспектов общения в сети Интернет посвящено множество исследований [9-12].

Участники полилога в чате не видят друг друга, находятся на большом расстоянии, возможно, даже в разных странах. Они общаются при помощи текстовых сообщений, общение зачастую носит отложенный характер, как при обычной переписке. С другой стороны, чаты дают возможность непосредственного общения, в отличие от форумов они обладают более высокой интерактивностью и степенью вовлеченности участников в процесс общения. Чаты выполняют фатическую функцию общения, в них более непосредственно выражаются эмоции. Все эти аспекты более характерны для устного общения. Отсутствие ограничений тематики и выбора языковых средств, игнорирование лексических и синтаксических норм также приближают чаты к устной неподготовленной речи, в которой часто совершаются речевые ошибки, а тема беседы меняется порой совершенно неожиданным образом.

Преимущественно текстовое общение было на заре существования чатов. Расширение технических возможностей сети Интернет и устройств коммуникации (компьютеров, телефонов, планшетов и т. п.) позволило уйти от многословных сообщений [13].
Уже в одном из первых популярных мессенджеров ISQ стали использоваться пиктограммы - смайлы, эмодзи. Посредством этих пиктограмм стало возможно не описывать эмоции, а передавать их изображением. Здесь можно провести параллель с мимикой и жестами как экстралингвистическими средствами устного общения (рис. 1).

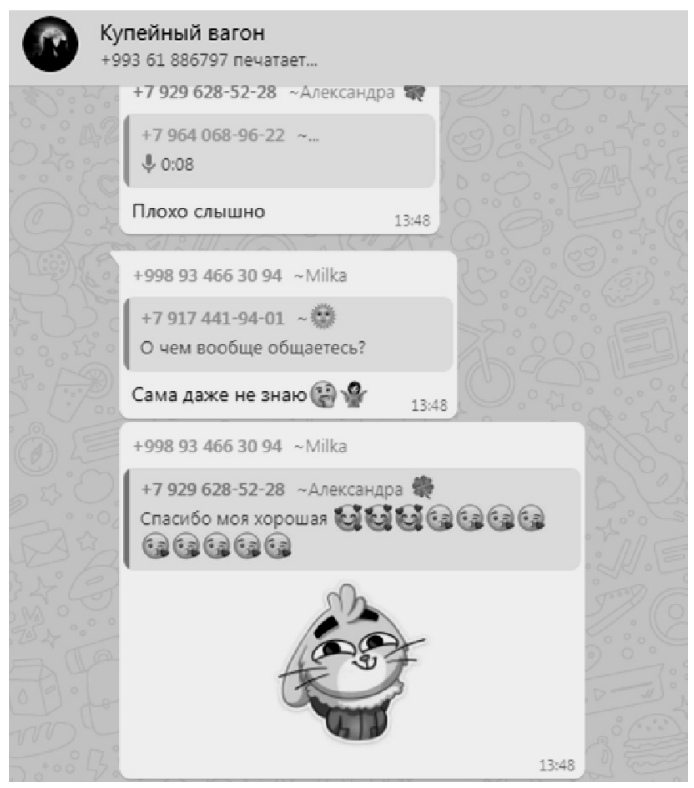

Puc. 1. Примеры выражения эмоций в интернет-чатах

Технические возможности шли дальше, допуская обмен фотографиями, которые заменяют целые тексты описательного характера. Затем появилась возможность передавать в чатах видеофайлы и аудиозаписи, в том числе голосовые сообщения.

Использование видео- и аудиоконтента еще более приблизило чаты к устной форме общения. Так, фотография доступна для просмотра целиком, не имеет временной протяженности и начинает передавать информацию сразу как письменный текст (рис. 2).

В отличие от фотографии, видео- и аудиофайлы имеют протяженность во времени, их нельзя «окинуть взглядом» одномоментно. Из-за этого они имеют и специфическое отображение в истории чата: видеозапись представлена одним кадром, аудиозапись особым изображением.

Что касается представленности каждого из видов сообщений - текстовое, эмодзи, аудиозапись, видеофайл или GIF-изображение, - то количество того или иного вида зависит от целей создания чата, правил поведения в нем, от состава и количества участников, их возраста, пола и т. д.

Как правило, контент задается первыми двумя факторами - целями и правилами чата. Так, для проведения исследования мы зарегистрировались в нескольких группах разной направленности и в разных 


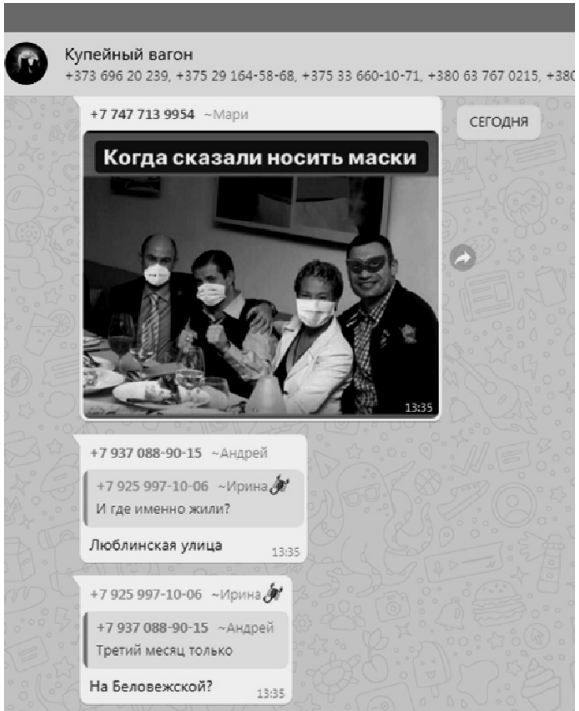

Puc. 2. Пример использования средств мультимедиа в интернет-чатах

мессенджерах. Для сравнения остановимся на двух из них.

1. Группа «Купейный вагон» в мессенджере WhatsApp. Создана для непосредственного общения «здесь и сейчас». В описании группы дана следующая информация: «Группа 25+ создана для знакомства и общения и создания позитивного настроения. Обмен видео с юмором приветствуется. Ждем общчительных с чувством юмора. Троли, скандалисты, материинники - будете проходить - проходите мимо...» (URL: https://whatsism.com/18650-vse-svoi. html). Как видим, круг допущенных лиц ограничен не просто совершеннолетними, а более зрелыми людьми. Цели группы - общение для позитивного настроения, девиантная лексика и речевое поведение не допускаются.

Количество участников в группе постоянно меняется, на момент регистрации - 244 человека. За 2 часа нахождения в группе было получено 815 сообщений, из них 187 - текстовых (23\%), причем текстовых сообщений длиной более одного предложения зафиксировано всего лишь 11. В группе преобладают сообщения в виде смайлов и стикеров 301 сообщение (37\%), видеозаписи и файлы в формате GIF - 213 сообщений (26\%). Немного меньше фотографий - 98 сообщений (12\%). Аудиосообщений относительно мало - 16 (2 \%). Малое количество аудиосообщений можно объяснить тем, что обычно к ним прибегают для передачи большого объема информации, который неудобно записывать на смартфоне. Жанр же этого чата не предполагает длинных сообщений ни в письменном виде, ни в аудиозаписи.

Как видим, в данном чате преобладают черты устного общения.
2. Группа «Московская филармония» в социальной сети «Вконтакте» (https://vk.com/mosfilarmonia). В группе 36643 участника. Эта группа открытая, участником может стать любой пользователь, вне зависимости от возраста и пола. Кроме того, комментировать записи также может любой пользователь, даже если он не является участником группы. При этом все сообщения проходят модерацию на предмет содержания ссылок, рекламы, нецензурной лексики, оскорбительного контента и т. п.

Несмотря на то, что группа открыта для любых пользователей, ее выбирают преимущественно люди, чьи интересы, как личные, так и профессиональные, лежат в сфере искусства и музыкального исполнительства.

Чаты в этой группе более консервативны: они содержат подавляющее большинство текстовых сообщений, сопровождаемых смайлами или стикерами. Многие текстовые сообщения представляют собой высказывание, состоящее более чем из 1-2 предложений, а также сложные или осложненные предложения. Например, 29 марта 2020 г. проводилась онлайн-трансляция «“Домашний сезон” Московской филармонии: концерты без зрителей», в которой был представлен концерт Павла Милюкова (скрипка), Александра Рамма (виолончель) и Филиппа Копачевского (фортепиано). Чат с обсуждением онлайн-трансляции содержит 974 сообщения.

В анализируемом чате многие сообщения отражают специфику устной речи: интонационную оформленность, упрощенные, но при этом экспрессивные синтаксические конструкции, грамматические нарушения. Например:

(1) Ждем с нетерпением! - определенно-личное восклицательное предложение. В письменной речи, вне контакта между собеседниками и вне ситуации общения это предложение могло бы быть развернуто следующим образом: «(Mbl) Ждем с нетерпением начала кониерта!».

(2) Какое же вам огромное спасибо, дорогая Московская филармония! - грамматические нарушения, экспрессивная синтаксическая конструкция; наличие частиц, обращение. В строго понимаемой письменной речи это предложение выглядело бы примерно так: «Трудно выразить словами, насколько я вам благодарна, дорогая Московская филармония, за эту трансляцию!». Ср. сообщение в этом же чате: (3) Выражаю огромную благодарность Московской филармонии за прекрасные музыкальные вечера, за встречи с любимыми музыкантами и великую музыку!!! - здесь форма и лексическое наполнение соответствуют канонам письменной речи.

(4) Огромное спасибо!!! Звездный состав трио! Замечательная программа! Браво, Московская фи- 
лармония! Вы каждый день дарите нам ПРАЗДНИК! - парцеллированные конструкции; экспрессия выражена графически: тройные восклицательные знаки, прописными буквами выделено слово, на которое автор высказывания делает смысловое ударение. В письменной речи это предложение можно было бы представить так: «Огромное спасибо за конщерт такого уровня, за звездный состав трио и замечательно подобранную программу! Браво, Московская филармония! Вы каждый день дарите нам настоящчий праздник!».

(5) Прекрасно сыгранный ансамбль. Что тут скажешь... ПРОФИ... - экспрессия выражена графически: назывное предложение, многоточия, прописными буквами выделено слово, на которое автор высказывания делает смысловое ударение, причем слово разговорное. В письменной речи это высказывание могло бы иметь следующий вид: «Прекрасно сыгранный ансамбль. Это и неудивительно - ведь здесь выступают только профессиональ».

(6) БРАВО!!! - предложение-междометие, экспрессия выражена графически: тройные восклицательные знаки, громкость восклицания передана прописными буквами. Пожалуй, в письменной речи это сообщение не изменилось бы, поскольку оно представляет собой устоявшееся традиционное восклицание в знак одобрения артисту.

Часть сообщений представляет собой символическое изображение действий - аплодисменты, преподнесение цветов артистам и т. д.:

(7)

(8)

Эти сообщения невозможно вербализовать, действия, обозначаемые ими, возможны только при непосредственном взаимодействии сторон акта коммуникации.

Другие пиктограммы заменяют выражение эмоций: жесты одобрения, сердечки и др.:

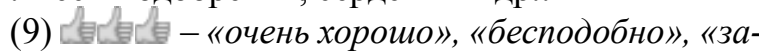
мечательно»,

(10)

(11)

(12) - «мне нравится то, что я вижу».

Пиктограммы, повторяемые несколько раз, выражают яркую эмоцию, передают сему 'очень', 'сильно': очень нравится, очень хорошо.

Таким образом, пиктограммы заменяют мимику и жесты, характерные для непосредственного общения. Именно поэтому чаты приближены к устной форме общения [14].

Тем не менее, несмотря на всю близость к устному общению, многие сообщения в чате обладают всеми признаками письменной речи: состоят из сложных или осложненных предложений, выражают развернутую мысль, в них используются ряды одно- родных членов, много оценочных прилагательных, характеризующих предметы или эмоции, отвлеченных существительных, используется книжная лексика:

(13) Как нам сейчас нужен Чайковский с его человечностью, трагизмом и просветлением! Он прямо там незримо в зале присутствует! - В устной речи говорящий стремился бы избежать книжной лексики (трагизм, просветление, незримо). Такое содержание в устной форме передавалось бы приблизительно так: «Как нам сейчас нужен Чайковский! Его музыка человечная и понятная, то, что сейчас нужно. Как будто он сам в зале присутствует»,

(14) Меня восхищает манера исполнения и звук Филиппа - героика в нем, глубина, наполненность. И какая простота и ясность фразировки, музыкальность такая душевная, без слашавости. Все ученики Доренского отличаются особым ярким звуком и бриллиантовой техникой. - В этом сообщении есть ряды однородных членов предложения, уточняющих мысль, автор, помимо книжной лексики (героика, слащавость, восхищает, терминов фразировка, техника), использует лексические средства выразительности (эпитет бриллиантовылй), инверсию как синтаксический прием (героика в нем, музыкальность такая душевная). Устное высказывание звучало бы примерно так: Мне нравится исполнение Филиппа душевное, но без слащавости, а техника просто бриллиантовая, и звук яркий.

(15) Классическая музыка очищает, возрождает и наполняет чистой божественной энергией... Музыкантьл, как Антон Пальч Чехов - врачеватели душ... - В данном сообщении явно выступают формальные признаки письменной речи: ряд однородных членов предложения, сравнительная конструкция. Смысловое содержание и лексическое наполнение соответствуют книжному стилю: отсылка к известному афоризму, апелляция к мировой литературной классике, эпитет божественная. В устной речи это сообщение можно было бы представить так: Классическая музыка очищиает. Музыканты - настоящуие врачеватели душ.

(16) Музыка сейчас - это какметроном в блокадном Ленинграде. Все время провожу эту параллель. Люблю наш город! Многие питериьь, мои друзья, коллеги музыканты, собираются каждый вечер у экранов, чтобы усльшиать транслячии Московской филармонии. - (17) Иван, прочитала Ваш предьлущчий комментарий и сразу вспомнила блокадный Ленинград и музыку Шостаковича... Подумала о том, что в годину лихих испьтаний в нашей стране всегда искусство было на передовой, поддерживало боевой дух, вселяло в сердияа людей надежду на победу. Вот и сейчас прекрасная МУЗЫКА - это глоток свежего воздуха для нас!!! - В этом обмене репликами 
(мини-диалоге) также преобладают признаки письменной речи: сложные предложения, осложненные однородными членами предложения, сравнительные конструкции. Лексическое наполнение соответствует тщательно продуманному высказыванию: используются книжные идиомы (проводить параллель, година лихих испьтаний = лихая година, быть на передовой, боевой дух), метафоры вселять в сердияа, глоток свежего воздуха. Но в сообщении (17) графическими средствами передаются интонационные особенности, экспрессивность высказывания, что приближает его к устной форме. Следует отметить, что в чате реплика в ответ на предыдущие комментарии создает иллюзию беседы - диалога или полилога. Такое явление характерно и распространено, и сообщения в этом случае приобретают больше признаков устной речи, особенно ответные реплики, например:

(18) Я прям благодарна карантину за возможность усльишать столько потрясающих кониертов подряд! - (19) Да, каждый вечер великолепные конизертыл. - Если реплика (18) представляет собой самостоятельное высказывание, соответствующее письменному общению, то ответная реплика (19) представляет собой предложение, мало понятное без контекста.

(20) После карантина пойдем [в Московскую филармонию]? -(21) Оптимизм - строить планы на после карантина. - В данном примере оба предложения являются неполными по структуре и по содержанию, носят явно разговорный характер (грамматическая неправильность) и представляют собой аналог устной речи.

Сложное предложение не всегда служит признаком письменной речи. Большую роль играют лексические средства, используемые в высказывании. Так, следующее сообщение максимально приближено к устному высказыванию:

(22) Филипп сегодня в ударе, эмоционален, а то в шопеновский вечер мне казался каким-то уставшим, хоть и играл классно. - Идиома быть в ударе, оценочное наречие классно, союз а то, местоимение каким-то в сочетании с прилагательным носят разговорный характер и характерны больше для устного общения. В строго понимаемой письменной речи это предложение могло бы выглядеть следующим образом: Филипп сегодня великолепен, играет эмоционально. В иопеновский вечер он показался мне несколько устальм, хотя играл все равно замечательно.

С другой стороны, такие явления, как парцелляция, неполные предложения, широко известны как средства синтаксической выразительности [15]. Поэтому они могут специально применяться не как неподготовленная устная речь, спонтанное высказывание, свидетельствующее о фрагментарности мысли, а как подготовленное экспрессивное средство в письменной речи, например:

(23) А чувствуете, какая энергетика у исполнителей - все ведь вошло в правильное русло, нет растерянности, потому что мы-то здесь, они знают и чувствуют! И никто уже про пустой зал не думает и внимания на это не обращуает. Ни мы, ни они!

У нас свой зрительный зал. Огромный!

А в битве за Жизнь музыка всегда побеждает!

Чайковский нам про это говорит.

(24) Какая нежность у скрипки. Божественный звук. Небесная чистота. И сколько земной любви и страсти. Петр Ильич радуется сейчас!

В примерах 23-24 парцелляция служит для намеренного расчленения единой синтаксической модели предложения на интонационно обособленные отрезки с целью актуализации наиболее важной части высказывания. Синтаксический разрыв предложения маркирован точкой или другим знаком конца предложения, что приводит к увеличению частотности употребления финального знака, а при зрительном восприятии текста - к его интонированию. Парцелляция - это отсечение части предложения. Для неподготовленной устной речи больше характерно присоединение - связь, заключающаяся в добавлении дополнительной информации к уже высказанной фразе. Интонация при присоединении несколько иная, чем при парцелляции. Так, в устной речи примеры 23-24 звучали бы несколько иначе, с более длинными паузами: И никто уже про пустой зал не думает и внимания на это не обращает... Ни мыл, ни они!.. У нас свой зрительный зал... Огромный!; Какая нежность у скрипки... Божественный звук... Небесная чистота... И сколько земной любви и страсти... Петр Ильич радуется сейчас! Присоединение как синтаксический прием хорошо виден в следующем сообщении:

(25) Сколько в этой музыке любви. И сколько жизни.

И как вдохновенно звучат виолончель и рояль человеческими голосами поют.

Или ангельскими... - информация каждого последующего предложения нанизывается на предыдущее по мере движения мысли, а не отсекается от него, как при парцелляции. Однако лексическое наполнение данного сообщения заставляет отнести это высказывание к подготовленной письменной речи, к ряду экспрессивных высказываний.

В чатах некоторые текстовые сообщения сопровождаются пиктограммами, которые привносят в письменную речь мимику и жесты, т. е. приближают к устной речи:

(26) Получаю Огромное Наслаждение на кониертах «Домашнего сезона». Спасибо организаторам!!! (Трио вне всяких похвал!!!!! Брависсимо!!!! 
В такое непростое время получаем столько захватьвающих, переполняющчи душу эмоцчии. Спасибо, что дают возможность сделать передыику в постоянной гонке за право сущуествовать - В данном сообщении перемежаются признаки устной и письменной речи, добавляются жесты, экспрессия.

В целом, в данном чате сообщения распределяются примерно поровну между тремя видами: текстовые, сообщения-смайлы, текстовые сообщения, сопровождаемые смайлами. Аудиосообщений и видеозаписей в данном чате не обнаружено. Данный чат больше приближен к письменной форме общения с элементами устной речи, где мимика и жесты заменены смайлами.

Таким образом, невозможно определенно сказать, к какому типу речи принадлежат все чаты, так как в них могут использоваться разнообразные современные средства общения: текст, пиктограммы, фото, гифки, видео- и аудиозаписи. Сами чаты имеют разный характер в зависимости от темы или целей создания, от круга интересов людей, поддерживающих общение посредством того или иного чата. Для определения типа речи, к которому принадлежит тот или иной чат, нужно анализировать его непосредственное содержание. Такие средства общения в чате, как смайлы (стикеры, эмодзи), аудиосообщения, видеозаписи, приближают чаты к устной форме общения. Традиционные текстовые сообщения и фотографии - средства письменной речи.

\section{Заключение}

Проведенное исследование показало, что устный характер коммуникации в группе «Купейный вагон» в мессенджере WhatsApp продиктован в основном жанром чата, обусловленным целью создания «Купейного вагона» - неформальное общение для знакомства и хорошего настроения. Данным жанром предполагается, что участники группы не так хорошо знакомы друг с другом, чтобы обмениваться длинными сообщениями в письменном виде или аудиозаписями, которые также служат зачастую для передачи большого объема информации. Более сложная ситуация с определением вида текста и коммуникации наблюдается в группе «Московская филармония» в социальной сети «Вконтакте». Участники группы объединены интересами в сфере искусства, некоторые профессионально вовлечены в сферу музыки, многие являются любителями музыкального исполнительства и музыки в целом Московской филармонии, что объясняет в чатах большое количество текстовых сообщений, продиктованных необходимостью коммуникантов поделиться впечатлениями, выразить свои эмоции. Последнее продемонстрировано сопровождением комментариев смайлами, стикерами, большим количеством воскли- цательных знаков, экспрессивными синтаксическими конструкциями, что приближает многие сообщения к устной речи. Специфику устного общения можно проследить также в допущении грамматических ошибок, использовании неосложненных синтаксических предложений в группе. Однако в чатах есть и наглядные примеры письменной речи: осложненные и сложные конструкции синтаксиса, лексические средства. Стоит заметить, что не всегда, к примеру, использование сложной конструкции автоматически относит текст к письменной коммуникации, так как важно проанализировать также его в характере использования лексических единиц и средств, а наличие парцелляции, которую обычно относят к устной речи за выражение фрагментарности и спонтанности мысли, может свидетельствовать о взвешенном, осознанном употреблении ее автором, что тогда будет причислять ее к средству письменного текста. Итак, чтобы разграничить устные и письменные тексты на примере интернет-чатов, необходимо анализировать много лингвистических (структура предложения, лексические единицы, средства выражения экспрессии) и экстралингвистических (жанр чата, тема и цель создания, возраст коммуникантов) признаков. Следует отметить, что новая устно-письменная форма коммуникации не только объединяет разграничивающие эти два вида текстов характеристики, но и обладает собственными особенностями за счет технических возможностей интернет-среды.

\section{ЛИТЕРАТУРА}

1. Арутюнова Н. Д. Жанры общения // Человеческий фактор в языке. Коммуникация, модальность, дейксис. М. : Наука, 1992. 280 с.

2. Андреева C. В. Речевые единицы устной русской речи. Система, зоны употребления, функции. Изд. 2-е. М. : КомКнига, 2006. 192 с.

3. Дельбрюк Б. Основные вопросы исследования языка. М. : Наука, 1984. 191 с.

4. Шаклеин В. М. Предикаты устного и письменного текстов как инструменты аргументации в аспекте НЛП // Вестник Рос. ун-та дружбы народов. Сер.: Русский и иностранные языки и методика их преподавания. 2013. № 1. C. 5-9.

5. Филатова E. В. Русская речь и ее реальные исходные единицы // Русистика. 2019. № 3 (17). С. 315-325.

6. Ватсон Е. Р. Сравнительная фонетика английского и русского языков. М. : МАКС Пресс, 2011. 121 с.

7. Гаузенблас К. О характеристике и классификации речевых произведений // Новое в зарубежной лингвистике. М. : Прогресс, 1978. С. 57-78.

8. Гальперин И. Р. Текст как объект лингвистического исследования. М. : КомКнига, 2006. 144 с.

9. Ахренова Н. А. Доминанты современной интернет-лингвистики : дис. ... д-ра филол. наук. Мытищи, $2018.363 \mathrm{c}$.

10. Голошубина О. К. Комплексное моделирование речевого жанра «разговор в мессенджере» : дис. ... канд. филол. наук. Омск, 2017. 175 с. 
11. Карпов Э. С. Функционирование сленга в дискурсе интернет-коммуникаций : дис. ... канд. филол. наук. М., 2016. 164 с.

12. Патрушева Л. С. Форум как речевой жанр интернет-дискурса : дис. ... канд. филол. наук. Ижевск, 2015. 183 c.

13. Бутенко Ю. И., Михайлова М. Д. Создание и функционирование текстов в сети Интернет // Филологические науки. Научные доклады высшей школы. 2020. № 4. С. 107-113.

14. Лысенко С. А. Устная и письменная речь, вопросы взаимодействия // Язык и национальное сознание. 2009. Вып. 12. С. 131-137.

15. Москальская О. И. Проблемы системного описания синтаксиса. М. : Высшая школа, 2013. 258 с.

\section{REFERENCES}

1. Arutyunova N. D. ZHanry obshcheniya [Genres of communication]. In: CHelovecheskij faktor v yazyke. Kommunikaciya, modal'nost', dejksis [The human factor in language. Communication, Modality, Deixis]. M. : Nauka, 1992. $280 \mathrm{p}$.

2. Andreeva C. B. Rechevye edinicy ustnoj russkoj rechi. Sistema, zony upotrebleniya, funkcii [Speech units of oral Russian speech. System, zones of usage, functions]. Izd. 2-e. M. : KomKniga, 2006. 192 p.

3. Del'bryuk B. Osnovnye voprosy issledovaniya yazy$k a$ [Basic Issues of Language Research]. M.: Nauka, 1984. $191 \mathrm{p}$.

4. SHaklein V. M. Predikaty ustnogo i pis'mennogo tekstov kak instrumenty argumentacii v aspekte NLP [Predicates of oral and written texts as tools of argumentation in the aspect of NLP]. In: Vestnik Rossijskogo universiteta druzhby narodov. Seriya: Russkij $i$ inostrannye yazyki $i$ metodika ih prepodavaniya. 2013. No. 1. Pp. 5-9.

5. Filatova E. V. Russkaya rech' i ee real'nye iskhodnye edinicy [Russian speech and its real initial units]. In: $R u$ sistika. 2019. No. 3 (17). Pp. 315-325.

Московский государственный технический университет имени Н. Э. Баумана

Бутенко Ю. И., кандидат технических наук, доцент кафедры «Романо-германские языки»

E-mail: iubutenko@bmstu.ru

Шершнева Е. А., студент

E-mail: shershnevaea@student.bmstu.ru

Поступила в редакичюю 8 мая 2021 2.

Принята к публикачии 15 октября 20212.

\section{Для цитирования:}

Бутенко Ю. И., Шершнева Е. А. Аспекты разграничения устных и письменных текстов на примере интернет-чатов // Вестник Воронежского государственного университета. Серия: Лингвистика и межкультурная коммуникация. 2021. № 4. C. 20-27. DOI: https://doi. org/10.17308/lic.2021.4/3807
6. Vatson E. R. Sravnitel'naya fonetika anglijskogo $i$ russkogo yazykov [Comparative phonetics of the English and Russian languages]. M.: MAKS Press, 2011. 121 p.

7. Gauzenblas K. O harakteristike i klassifikacii rechevyh proizvedenij [On the Characteristics and Classification of Speech Works]. In: Novoe v zarubezhnoj lingvistike. M.: Progress, 1978. Pp. 57-78.

8. Gal'perin I. R. Tekst kak ob"ekt lingvisticheskogo issledovaniya [Text as an Object of Linguistic Research]. M.: KomKniga, 2006. 144 p.

9. Ahrenova N. A. Dominanty sovremennoj internet-lingvistiki [The dominants of modern Internet linguistics]: dissertaciya ... doktora filologicheskih nauk. Mytishchi, 2018. 363 p.

10. Goloshubina O. K. Kompleksnoe modelirovanie rechevogo zhanra «razgovor $v$ messendzhere» [Complex modeling of the speech genre "conversation in the messenger] : dissertaciya ... kandidata filologicheskih nauk. Omsk, 2017. 175 p.

11. Karpov E. S. Funkcionirovanie slenga v diskurse internet-kommunikacij [Functioning of slang in the discourse of Internet communications]: dissertaciya ... kandidata filologicheskih nauk. Moskva, 2016. 164 p.

12. Patrusheva L. S. Forum kak rechevoj zhanr internet-diskursa [Forum as a speech genre of Internet discourse]: dissertaciya ... kandidata filologicheskih nauk. Izhevsk, 2015. 183 p.

13. Butenko IU. I., Mihajlova M. D. Sozdanie i funkcionirovanie tekstov $\mathrm{v}$ seti Internet [Creation and functioning texts in the internet]. In: Filologicheskie nauki. Nauchnye doklady vysshej shkoly. 2020. No. 4. Pp. 107-113.

14. Lysenko S. A. Ustnaya i pis'mennaya rech', voprosy vzaimodejstviya [Oral and written speech, issues of interaction]. In: YAzyk i nacional'noe soznanie. 2009. Vyp. 12. Pp. 131-137.

15. Moskal'skaya O. I. Problemy sistemnogo opisaniya sintaksisa [Problems of system description of syntax]. M.: Vysshaya shkola, 2013. 258 p.

Bauman Moscow State Technical University

Butenko Yu. I., Candidate of Technical Sciences, Associate Professor of the Romance-Germanic Languages Department

E-mail: iubutenko@bmstu.ru

Shershneva E. A., Student

E-mail: shershnevaea@student.bmstu.ru

Received: 8 May 2021

Accepted: 15 October 2021

\section{For citation:}

Butenko Yu. I., Shershneva E. A. The problem of distinction between oral and written texts on Internet chats material. Proceedings of Voronezh State University. Series: Linguistics and Intercultural Communication. 2021. No. 4. Pp. 20-27. DOI: https://doi.org/10.17308/lic.2021.4/3807 